\title{
Synthesis and NMR Characterization of the Alternating Copolymer of Methyl $\alpha$-Fluoroacrylate with Styrene
}

\author{
Ramendra N. MAJUMDAR, ${ }^{\dagger}$ Fu-tyan LIN, ${ }^{*}$ and H. James HARwOOD \\ Institute of Polymer Science, The University of Akron, \\ Akron, Ohio 44325, U.S.A. \\ * Department of Chemistry, University of Pittsburgh, \\ Pittsburgh, Pa. 15260, U.S.A.
}

(Received August 16, 1983)

\begin{abstract}
Alternating copolymers of methyl $\alpha$-fluoroacrylate (MFA) with styrene (S), $\alpha$ deuteriostyrene and $\beta, \beta$-dideuteriostyrene were prepared at $-15^{\circ} \mathrm{C}$ using ethyl aluminium sesquichloride as a complexing agent. The $300 \mathrm{MHz}{ }^{1} \mathrm{H}, 20 \mathrm{MHz}{ }^{13} \mathrm{C}, 75 \mathrm{MHz}{ }^{13} \mathrm{C}$, and $282 \mathrm{MHz}$ ${ }^{19} \mathrm{~F}$ NMR spectra of the copolymers were recorded and analyzed to obtain information about their stereochemical structures. The coisotacticity parameter of poly(MFA-alt-S) was determined to be 0.66 .

KEY WORDS Methyl $\alpha$-Fluoroacrylate / Styrene / $\alpha$-Deuteriostyrene / $\beta, \beta$ Dideuteriostyrene / Alternating Copolymer / ${ }^{1} \mathrm{H}$ NMR $/{ }^{13} \mathrm{C}$ NMR $/{ }^{19} \mathrm{~F}$ NMR / ${ }^{1} \mathrm{H}$ 2DJNMR / Coisotacticity Parameter /
\end{abstract}

Steric effects of the $\alpha$-substituents of donor and acceptor monomers govern the stereochemistry of the alternating copolymers obtained when these monomers are copolymerized in the presence of monomer complexing agents. Thus, copolymerizations of $\alpha$-methylstyrene with methyl methacrylate ${ }^{1}$ or methacrylonitrile ${ }^{2}$ give predominately cosyndiotactic alternating copolymers because of steric repulsion between the $\alpha$-methyl substituents in the two monomers. On the other hand, copolymerizations of styrene with methyl acrylate ${ }^{1}$ or methyl methacrylate ${ }^{1}$ or of $\alpha$-methylstyrene with methyl acrylate ${ }^{1}$ or acrylonitrile ${ }^{3}$ give atactic copolymers. Little is known, however, about how the polar nature of $\alpha$-substituents influences the stereochemistry of alternating copolymers. The limited data that are available are conflicting. Thus, alternating copolymers of methyl $\alpha$-chloroacrylate with styrene are reported to have coisotacticity $\left(\sigma_{\mathrm{AB}}\right)$ values of 0.43 and 0.69 by Gaylord et $a l^{4}$ and by
Yokota et al., ${ }^{5}$ respectively. To learn more about this aspect of alternating copolymerization chemistry, it seemed advisable to investigate alternating copolymerization systems that employed monomers bearing $\alpha$-fluoro substituents. An additional advantage of studying such copolymerizations was that ${ }^{19} \mathrm{~F}$ NMR spectroscopy could be used to investigate the microstructures of the copolymers produced. This paper concerns the stereochemistry and NMR spectra of the alternating copolymer that results when methyl $\alpha$ fluoroacrylate is copolymerized with styrene in the presence of ethyl aluminium sesquichloride.

\section{EXPERIMENTAL}

\section{Monomers}

Methyl $\alpha$-fluooroacrylate was synthesized by a five step process starting from methyl acrylate which was brominated to obtain methyl

\footnotetext{
${ }^{\dagger}$ Present address: Disposible Products Division, 230-03F-06 3 M Center, St. Paul, Minnesota 55144, U.S.A.
} 
$\alpha, \beta$-dibromopropionate. ${ }^{6}$ This was treated with quinoline to obtain methyl $\alpha$-bromoacrylate $^{7}$ which was then brominated to obtain methyl $\alpha, \alpha, \beta$-tribromopropionate. Reaction of this material with $\mathrm{SbF}_{3} / \mathrm{SbCl}_{5}$ yielded methyl $\alpha, \beta$-dibromo- $\alpha$-fluoropropionate ${ }^{8}$ which was then debrominated using a mixture of zincthiourea-diphenyl ether ${ }^{9}$ to obtain methyl $\alpha$ fluoroacrylate containing some methyl acrylate as a side product. This impurity was removed by its preferential reactivity with cyclopentadiene,,$^{9}$ and methyl $\alpha$-fluoroacrylate was distilled, bp $43^{\circ} \mathrm{C} / 101$ mbar (lit. ${ }^{10,11} \mathrm{bp}$ $\left.95^{\circ} \mathrm{C} ; 32^{\circ} \mathrm{C} / 65 \mathrm{mbar}\right) .{ }^{* 1} \mathrm{H}$ NMR coupling constants of this monomer have been reported by Elkik et al. ${ }^{10}$ and also by Pittman et al. ${ }^{11}$ but the results do not agree. To rectify this situation, the olefinic proton resonance of this monomer was recorded and analyzed using the LAOCN3 program of Bothner-By and Castellano. ${ }^{12}$ The chemical shifts and coupling constants that were evaluated by this procedure agree closely with those reported by Elkik et al. ${ }^{10}$ The observed and calculated spectra along with the values of the chemical shifts and coupling constants are reported in Figure 1.

Commercial styrene was freshly distilled over $\mathrm{CaH}_{2}$ prior to use. $\alpha$-Deuteriostyrene ${ }^{13}$ and $\beta, \beta$-dideuteriostyrene ${ }^{14}$ were prepared by known methods.

\section{Alternating Copolymer Synthesis}

Methyl $\alpha$-fluoroacrylate $(2.2 \mathrm{~g}, 0.021 \mathrm{~mol})$, toluene $(10 \mathrm{ml})$, and a solution of ethyl aluminium sesquichloride $(1.98 \mathrm{~g}, 0.016 \mathrm{~mol})$ in tol-

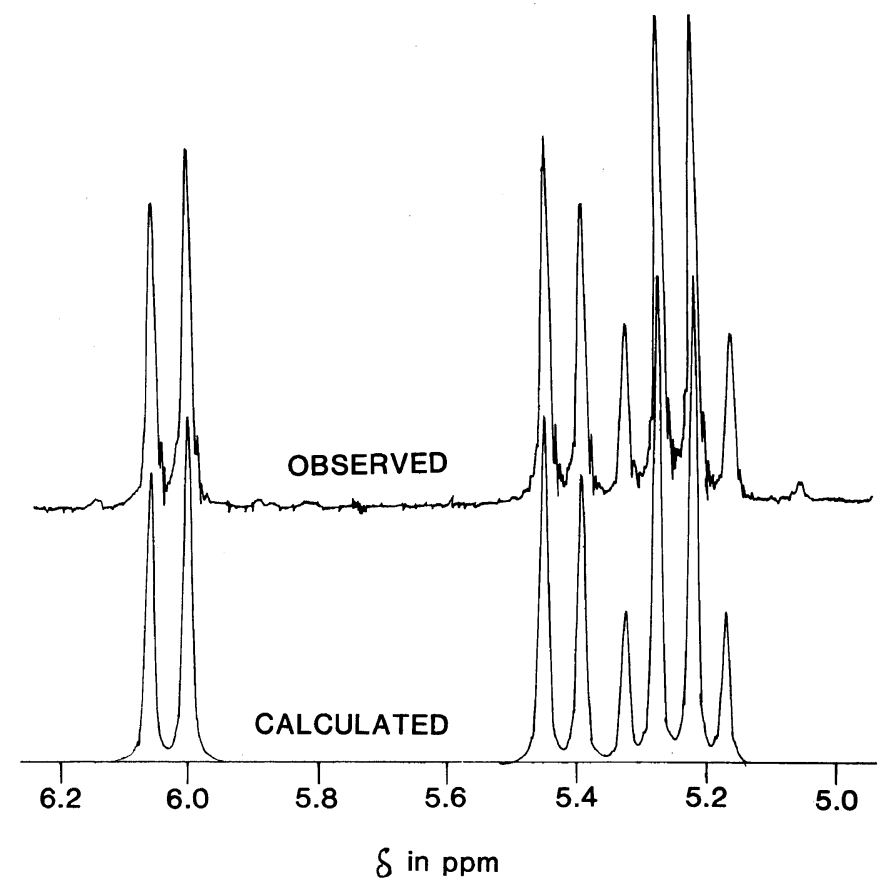

Figure 1. $60 \mathrm{MHz}$ olefin proton resonance of methyl $\alpha$-fluoroacrylate. The calculated spectrum is based on the following parameters: $\delta_{\mathrm{A}}=5.32 \mathrm{ppm} ; \delta_{\mathrm{B}}=5.67 \mathrm{ppm} ; J_{\mathrm{A}-\mathrm{B}}=3.3 \mathrm{~Hz} ; J_{\mathrm{A}-\mathrm{F}}=13.1 \mathrm{~Hz} ; J_{\mathrm{B}-\mathrm{F}}=44.3 \mathrm{~Hz}$.

* A referee has asked us to compare our synthesis procedure with that reported by Pittman, ${ }^{11}$ which was published after our experimental work was completed. Although we have not investigated his procedure, we note that it employs methyl $\alpha$-fluoroacetate, a highly toxic substance. Furthermore, his use of ether as a solvent complicates purification of the monomer because methyl $\alpha$-fluoroacrylate forms an azeotrope with ether. Other comments are to be found in references 8 and 9. 
Table I. Copolymerization of methyl $\alpha$-fluoroacrylate (MFA) complexed with ethyl aluminium sesquichloride (EASC) ${ }^{\mathrm{a}}$ with styrene, $\alpha$-deuteriostyrene and $\beta, \beta$ dideuteriostyrene in toluene at $-15^{\circ} \mathrm{C}$

\begin{tabular}{|c|c|c|c|c|}
\hline \multirow{3}{*}{ 2nd monomer } & \multirow{3}{*}{$\begin{array}{l}\text { Feed } \\
\text { mol\% } \\
\text { MFA }\end{array}$} & \multirow{3}{*}{$\begin{array}{c}\text { Polymeri- } \\
\begin{array}{c}\text { zation } \\
\text { time }\end{array} \\
\frac{h}{h}\end{array}$} & \multirow{3}{*}{$\frac{\text { Yield }^{\mathrm{b}}}{\%}$} & \multirow{3}{*}{$\frac{\text { Copolymers }}{\mathrm{mol}^{\mathrm{o}} \%}$} \\
\hline & & & & \\
\hline & & & & \\
\hline Styrene & 39.6 & 16 & 7.4 & 50.3 \\
\hline$\alpha-d_{1}-$ Styrene & 53.3 & 24 & 10.8 & 49.1 \\
\hline$\beta, \beta-d_{2}$-Styrene & 52.1 & 12 & 8.6 & 50.7 \\
\hline
\end{tabular}

a $[\mathrm{EASC}] /[\mathrm{MFA}]=0.5-0.8$.

b [(Total wt. of polymer)/(Total wt. of two monomers) $] \times 100$.

c From $60 \mathrm{MHz}{ }^{1} \mathrm{H}$ NMR spectra.

uene $(9 \mathrm{ml})$ were added under nitrogen, to a flask that was cooled in an acetone/Dry Ice bath. The reaction mixture was stirred and allowed to come to room temperature. Then it was again cooled with acetone/Dry Ice and styrene $(3.3 \mathrm{~g}, 0.032 \mathrm{~mol})$ was added. The reaction mixture was kept in a freezer at $-15^{\circ} \mathrm{C}$ for $16 \mathrm{~h}$ and then it was poured into methanol containing $\mathrm{HCl}$ to precipitate the copolymer. It was purified by reprecipitation from chloroform solution into cyclohexane. The yield was $0.41 \mathrm{~g}(7.4 \%)$.

The above-mentioned procedure was repeated using $\alpha$-deuteriostyrene and $\beta, \beta$ dideuteriostyrene as the donor monomer. Table I shows monomer feed compositions, conversions and compositions of copolymers obtained.

\section{Statistical Copolymer Synthesis}

Methyl $\alpha$-fluoroacrylate $(2.75 \mathrm{~g}, 0.026 \mathrm{~mol})$, styrene $(1.12 \mathrm{~g}, 0.011 \mathrm{~mol})$ and $2,2^{\prime}$-azobisisobutyronitrile $(0.01 \mathrm{~g})$ were introduced into a glass vial. The mixture was degassed and sealed under vacuum. It was heated in an oil bath at $60^{\circ} \mathrm{C}$ for $5 \mathrm{~h}$ and $30 \mathrm{~min}$ and then poured into methanol to precipitate the polymer. The polymer was purified by reprecipi- tation into methanol from chloroform solution, filtered and then dried under vacuum to constant weight. The yield was $0.72 \mathrm{~g}$ $(18.6 \%)$. NMR analysis indicated it to contain $48 \mathrm{~mol} \%$ styrene units.

\section{NMR Studies}

$300 \mathrm{MHz}{ }^{1} \mathrm{H}$ NMR spectra of the copolymers in $\mathrm{CDCl}_{3}$ solution at $55^{\circ}$ were recorded using Varian HR-300 (CW mode) and Bruker WH-300 (FT mode) spectrometers. The FT spectra were recorded using a $70^{\circ}$ tip angle, a one second delay between pulses, a $32 \mathrm{~K}$ data size and a $3300 \mathrm{~Hz}$ sweep width.

$20 \mathrm{MHz}{ }^{13} \mathrm{C}$ NMR spectra of the polymers in $\mathrm{CDCl}_{3}$ solution at room temperature were recorded using a Varian CFT-20 NMR spectrometer with a $4 \mathrm{~K}$ data size, a $4000 \mathrm{~Hz}$ sweep width, a $90^{\circ}$ tip angle and a $0.5 \mathrm{~s}$ delay between pulses.

$75 \mathrm{MHz}{ }^{13} \mathrm{C}$ NMR spectra of the polymers in $\mathrm{CDCl}_{3}$ solution at $55^{\circ}$ were recorded using the Bruker instrument, a $70^{\circ}$ tip angle, a delay time of $0.5 \mathrm{~s}$, a $16 \mathrm{~K}$ data size and a $20,000 \mathrm{~Hz}$ sweep width.

$282 \mathrm{MHz}{ }^{19} \mathrm{~F}$ NMR spectra of the copolymers in chloroform solution at room temperature were recorded using the Bruker instrument with a $70^{\circ}$ tip angle, a delay time of $1 \mathrm{~s}$, a $16 \mathrm{~K}$ data size and a $10 \mathrm{~K} \mathrm{~Hz}$ sweep width. The chemical shift of $\mathrm{CFCl}_{3}$ was taken as zero and resonances upfield from it are assigned positive values. ${ }^{15}$

$300 \mathrm{MHz}{ }^{1} \mathrm{H}$ 2DJNMR spectra were recorded with the Bruker instrument using a regular Hahn spin-echo $\left(-d-90^{\circ}-\tau-180^{\circ}-\tau\right.$-echo $)$ sequence, with a delay (d) of $0.5 \mathrm{~s}$. The chemical shift domain width was $3300 \mathrm{~Hz}$ with a data size of $2 \mathrm{~K}$. The $J$-domain width was $25 \mathrm{~Hz}$ with a data size of 32 .

\section{RESULTS AND DISCUSSION}

\section{Copolymer Synthesis}

Copolymers of methyl $\alpha$-fluoroacrylate (MFA) with styrene (S), $\alpha$-deuteriostyrene or 


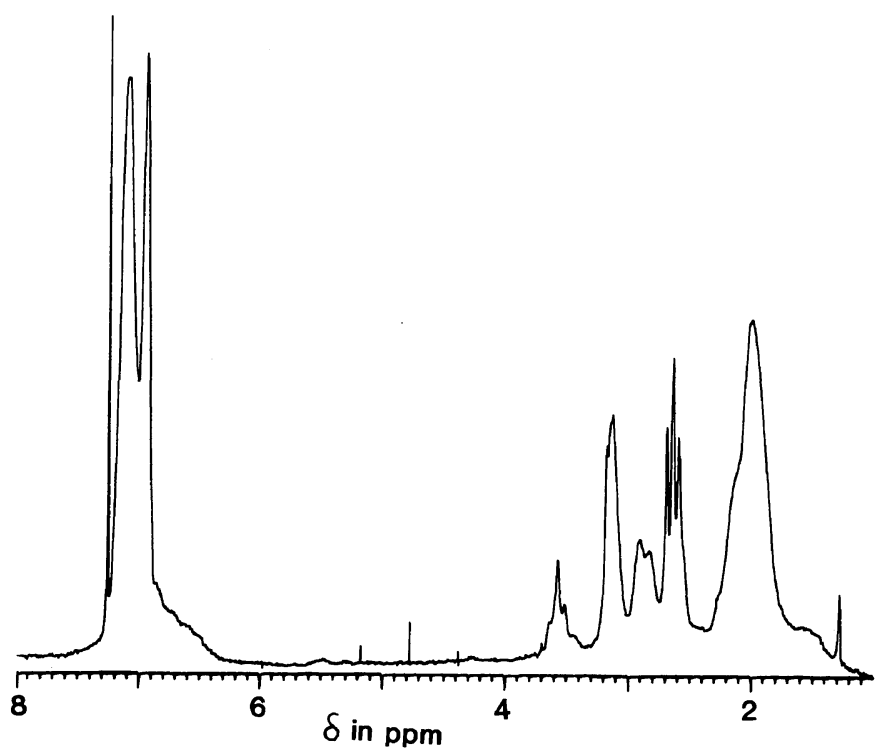

Figure 2. $300 \mathrm{MHz}{ }^{1} \mathrm{H}$ NMR spectrum of the alternating copolymer of methyl $\alpha$-fluoroacrylate with styrene in $\mathrm{CDCl}_{3}$ solution at $55^{\circ} \mathrm{C}$.

$\beta, \beta$-dideuteriostyrene were prepared using ethyl aluminium sesquichloride as the complexing agent in toluene at $-15^{\circ} \mathrm{C}$. The copolymers were shown to be equimolar for a few different feed ratios used (Table I) thus supporting their alternating structure. Additional evidence on this point is provided by the ${ }^{13} \mathrm{C}$ NMR spectra of the copolymers (vide infra).

\section{${ }^{1} H$ NMR Studies}

Figure 2 shows the $300 \mathrm{MHz}{ }^{1} \mathrm{H}$ NMR spectrum of the alternating copolymer of methyl $\alpha$-fluoroacrylate with styrene in $\mathrm{CDCl}_{3}$ solution. The aromatic proton resonance $(\delta=$ $6.5-6.7 \mathrm{ppm}$ ) consists of two intense signals having relative intensities of approximately $3: 2$ due to three (meta and para) and two (ortho) protons, respectively. The weak broad band at $\delta=\sim 6.8 \mathrm{ppm}$ may be due to the presence of some styrene-styrene dyads in the polymer, but this point is uncertain. Based on the relative intensities of the aromatic and aliphatic proton resonances, the copolymer contains $50.3 \mathrm{~mol} \%$ styrene. The resonances of the methoxy and methine protons are observed at $\delta=2.5-3.8 \mathrm{ppm}$ and are overlapped. The methylene proton resonances occur at $\delta=1.3-2.4 \mathrm{ppm}$. The aliphatic proton resonances were assigned by comparing the spectra of alternating copolymers prepared from methyl $\alpha$-fluoroacrylate with styrene, $\alpha$-deuteriostyrene and $\beta, \beta$-dideuteriostyrene. Thus, no resonance was evident at $\delta=2.7-3.0 \mathrm{ppm}$ in the spectrum of the MFA- $\alpha$-deuteriostyrene copolymer and resonance at $\delta=1.3-2.4 \mathrm{ppm}$ was less intense in the spectrum of the MFA- $\beta, \beta$-dideuteriostyrene copolymer than in the spectrum of the MFA-styrene copolymer. ${ }^{1} \mathrm{H}$ 2DJNMR experiments also support these assignments. Figure 3 shows ${ }^{1} \mathrm{H}$ 2DJNMR contour plots for the MFA-styrene copolymer. Due to their low concentration in the polymer and the fact that they are extensively coupled to other protons, the methine proton signals are not evident in the contour levels expressed in Figure 3. The methoxy proton resonances occur as single intense peaks in this figure and each methylene proton is responsible for four 


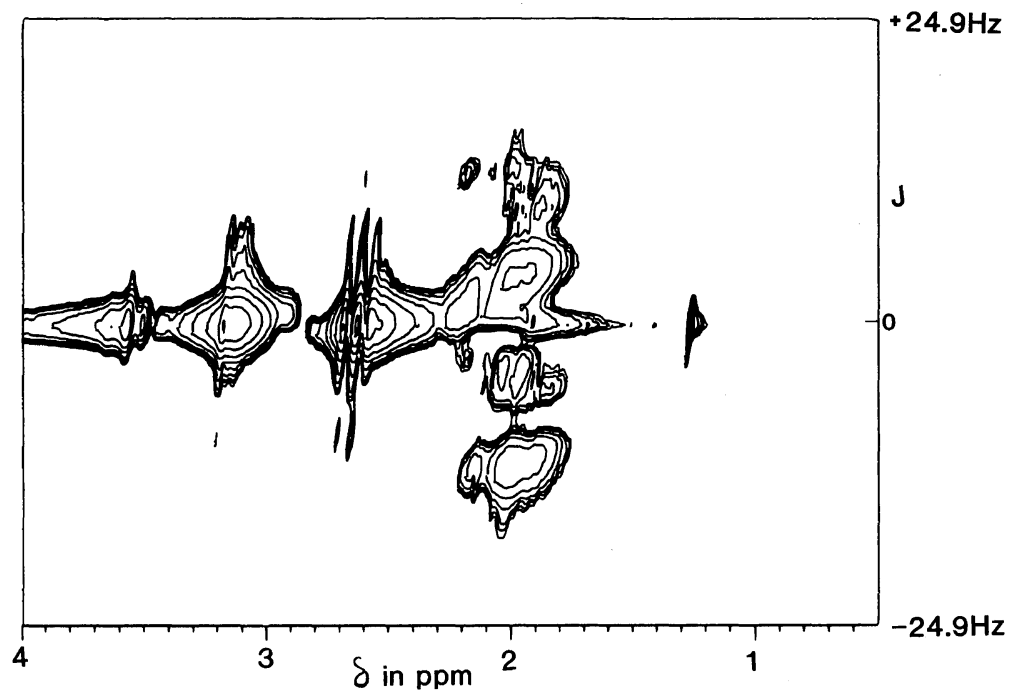

Figure 3. $300 \mathrm{MHz}{ }^{1} \mathrm{H} 2 \mathrm{DJNMR}$ contour plot of the alternating copolymer of methyl $\alpha$-fluoroacrylate with styrene.

peaks, two on each side of the zero coupling line, because of geminal $(\sim 15 \mathrm{~Hz})$ and vicinal $(\sim 7 \mathrm{~Hz})$ coupling.

On the basis of the above arguments, we conclude that the methoxy proton resonance of the copolymers occurs in three general areas: A $(\delta=3.3-3.7 \mathrm{ppm}), \mathrm{B}(\delta=3.0-3.3$ $\mathrm{ppm})$, and $\mathrm{C}(\delta=2.5-2.8 \mathrm{ppm})$. These resonances are assigned to $r r-,(m r+r m)$-, and $\mathrm{mm}$-stereosequence triads in order of increasing field, based on analogy to assignments developed previously for styrene-(methyl methacrylate) $)^{1,16}$ and styrene-(methyl $\alpha$-chloroacrylate $)^{5}$ copolymers and also based on the fact that the chemical shift of the $\mathrm{C}$-area was found to be dependent on temperature, while that of the A-area was almost independent of temperature. Blouin ${ }^{16}$ has shown that the chemical shifts of methoxy protons in $m m$-stereosequences in alternating copolymers derived from styrene, $\alpha$-methylstyrene, methyl

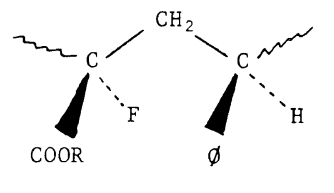

$\mathrm{m}$ acrylate and methyl methacrylate are very dependent on temperature, whereas those in $r r$-stereosequences are not. The effect was attributed to phenyl-carbomethoxy interactions that are favorable in the $\mathrm{mm}$-stereosequences at low temperatures. Such interactions are also possible in poly[(methyl $\alpha$-fluoroacrylate)-altstyrene] and it seems reasonable to use this concept for assigning methoxy proton resonance signals.

The relative intensities of the A-, B-, and Cmethoxy proton resonances in poly[(methyl $\alpha$-fluoroacrylate)-alt-( $\alpha$-deuteriostyrene)] are $0.15,0.42$, and 0.43 , respectively. Assuming a Bernoullian stereosequence distribution, these values are consistent with a coistotacticity parameter $\left(\sigma_{\mathrm{AB}}\right)$ of 0.66 , which is based on the $\mathrm{C}$-methoxy proton resonance area and is the probability that a MFA-styrene or styreneMFA placement in the copolymer has a meso (coisotactic) placement, viz.

or<smiles>[R20]C([CH2])[C@@](C)(F)CC(C)C</smiles> 
R. N. Majumdar, F.-t. Lin, and H. J. HaRwood

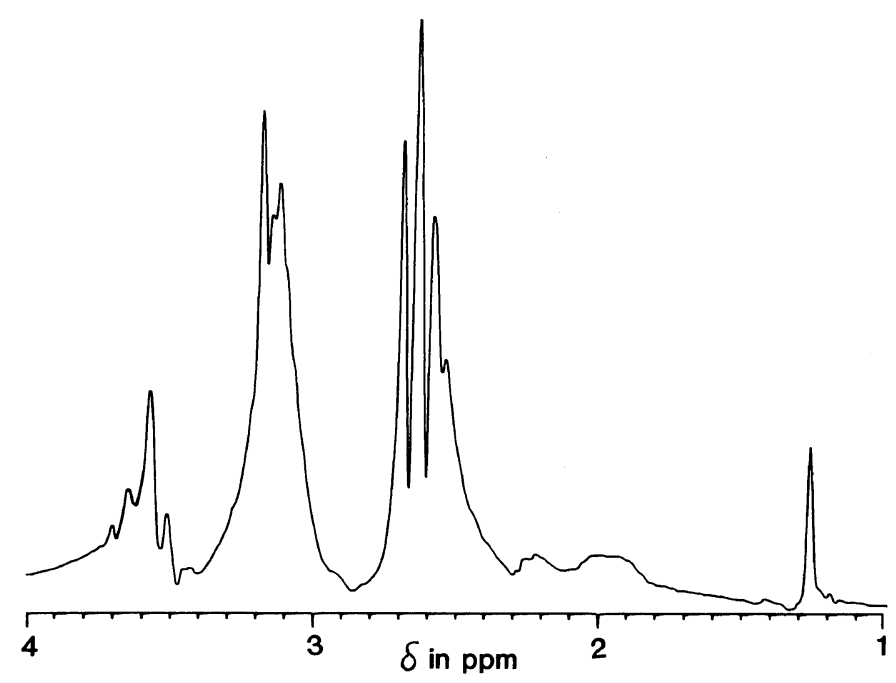

Figure 4. $300 \mathrm{MHz}^{1} \mathrm{H}$ 2DJNMR $J$-resolved projection (aliphatic region) of the alternating copolymer of methyl $\alpha$-fluoroacrylate with styrene.

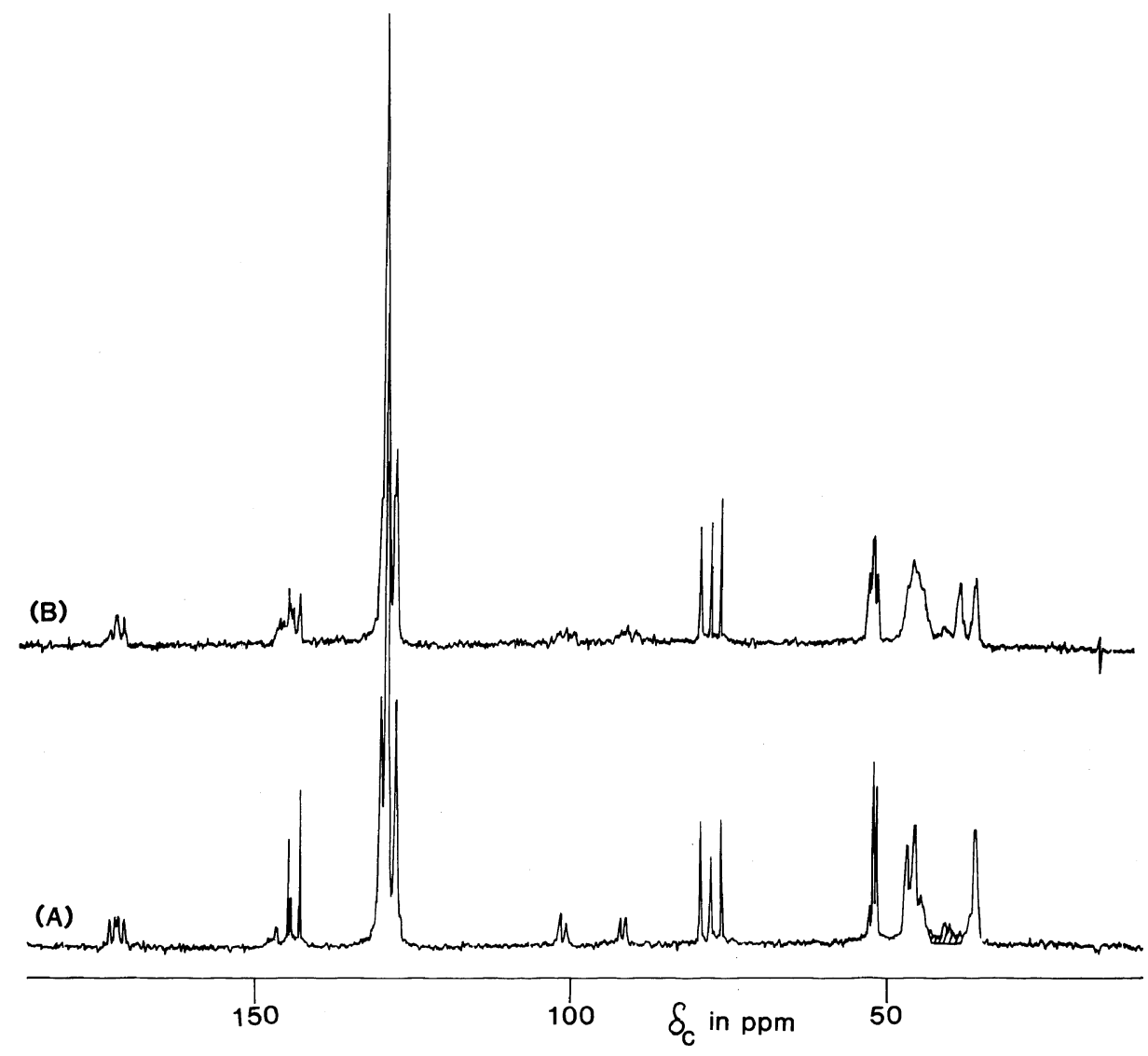

Figure 5. $20 \mathrm{MHz}^{13} \mathrm{C}$ NMR spectra of the copolymers of methyl $\alpha$-fluoroacrylate with styrene in $\mathrm{CDCl}_{3}$ solution at room temperature (A) alternating (B) statistical having $48 \mathrm{~mol} \% \mathrm{St}$. 
Thus, the relative intensities of the A-, B-, and $\mathrm{C}$-methoxy proton resonance areas should be $0.115,0.449$, and 0.436 if $\sigma_{\mathrm{AB}}=0.66$. The fine structure evident in the A- and C-methoxy proton resonance patterns is attributed to pentad stereosequences. This is defined especially well in the ${ }^{1} \mathrm{H}$ 2DJNMR $J$-resolved projection of this region that is shown in Figure 4. There is even an indication that some heptad stereosequences may be detected at about $\delta=2.5$ and $3.7 \mathrm{ppm}$.

The methine proton resonance of the alternating MFA-styrene copolymer $(\delta=2.8-3$ ppm) consists of several signals that are probably also due to stereosequence effects. This region accounts for $85 \%$ of the total methine resonance expected, which suggests that the resonances of $(m r+r m)$ and $m m$-triad stereosequences are observed in this region. The remainder of the methine proton resonance pattern seems to be overlapped with methoxy proton resonance signals. The methylene proton resonance area $(\delta=1.3-2.4 \mathrm{ppm})$ is $31 \%$ of the total resonance observed, in good agreement with the value of $30.8 \%$ that is calculated for the alternating copolymer.

\section{${ }^{13}$ C NMR Studies}

Figure 5 shows the $20 \mathrm{MHz}{ }^{13} \mathrm{C}$ NMR spectrum of the alternating MFA-styrene copolymer in $\mathrm{CDCl}_{3}$ solution at room temperature. Assignments for the various resonances observed in this spectrum are given in Table II. The methylene and methine carbon resonance assignments were made by comparing the spectra of alternating MFA-styrene, MFA- $\alpha$-deuteriostyrene, and MFA- $\beta, \beta$-dideuteriostyrene copolymers. The ${ }^{13} \mathrm{C}$ NMR spectra of the deuteriated copolymers were exactly the same as the spectrum of the undeuterated sample, except that the resonances of the deuterated carbons were broadened and of reduced intensity compared to those of the corresponding hydrogen-bearing carbons. In addition to these resonances, a group of signals (shaded) occurred at $\delta_{\mathrm{c}}=37-44 \mathrm{ppm}$. These are attributed to the incorporation of a small amounts of impurity or structural defects in the polymer chain. In fact, the methyl $\alpha$ fluoroacrylate used to prepare the copolymers contained a small amount of methyl acrylate. It was not possible to eliminate this impurity completely from the monomer by selective reaction with cyclopentadiene and it may be responsible for resonances observed at $\delta_{\mathrm{c}}=$ $37-44 \mathrm{ppm}$.

To confirm the alternating structure of the copolymer prepared in the presence of ethyl aluminium sesquichloride, its ${ }^{13} \mathrm{C}$ NMR spectrum was compared with that of a statistical copolymer of approximately equimolar composition. Significant differences were observed, particularly in the high field region as shown in Figure 5B. The resonance of the methine carbons in polystyrene is known to occur as a sharp signal at $\delta_{\mathrm{c}}=40.5 \mathrm{ppm}$. In the spectrum of the statistical copolymer, three methine carbon signals are observed at $\delta_{\mathrm{c}}=40.5,38.6$, and $36.0 \mathrm{ppm}$ due to $\mathrm{S}-\mathrm{S}-\mathrm{S}$, (S-S-MFA+ MFA-S-S), and MFA-S-MFA monomer

Table II. ${ }^{13} \mathrm{C}$ NMR Resonance assignments for poly[(methyl $\alpha$-fluoroacrylate)-alt-styrene]

Carbon $\quad \delta_{\mathrm{c}}(\mathrm{ppm}) \quad \mathrm{C}=\mathrm{O}$


sequence triads, respectively. In the spectrum of the copolymer prepared in the presence of ethyl aluminium sesquichloride (Figure 5A), a single sharp signal at $\delta_{\mathrm{c}}=36.1 \mathrm{ppm}$ strongly confirms its alternating structure. Moreover, the methoxy and methylene carbon resonance patterns are not so well defined in the statistical copolymer spectrum as in the spectrum of the alternating copolymer because the former contain multiple signals due to contributions from nonalternating monomer sequences.

Information about the stereochemical structure of poly(MFA-alt-styrene) can be obtained by analyzing the resonance patterns observed for the various carbons present. The interpretation of several of the patterns is complicated by $\mathrm{C}-\mathrm{F}$ spin-spin couplings, but all are consistent with a $\sigma_{\mathrm{AB}}$ value of 0.66 .

Figure 6 shows an expansion of the carbonyl carbon resonance pattern. It consists of two overlapped 3-signal patterns, each of which is believed to provide triad stereosequence distribution information. The patterns are separated by $27 \mathrm{~Hz}$, which is equal to the coupling constant between the carbonyl carbon and the $\alpha$-fluorine atoms. The separate patterns are identified as A, B, C and $\mathrm{A}^{\prime}, \mathrm{B}^{\prime}, \mathrm{C}^{\prime}$ (shaded) in Figure 6, although signals $A$ and $A^{\prime}$ are hard to identify because of their low intensity and the poor signal to noise ratio. The relative intensities of signals $\mathrm{A}, \mathrm{B},\left(\mathrm{A}^{\prime}+\mathrm{C}+\mathrm{B}^{\prime}\right)$, and $C^{\prime}$ were measured to be $0.04,0.21,0.51$, and 0.23 . If signals $A$ and $A^{\prime}$ are assigned to $r r$ stereosequences, $\mathbf{B}$ and $\mathrm{B}^{\prime}$ to $(m r+r m)$ -

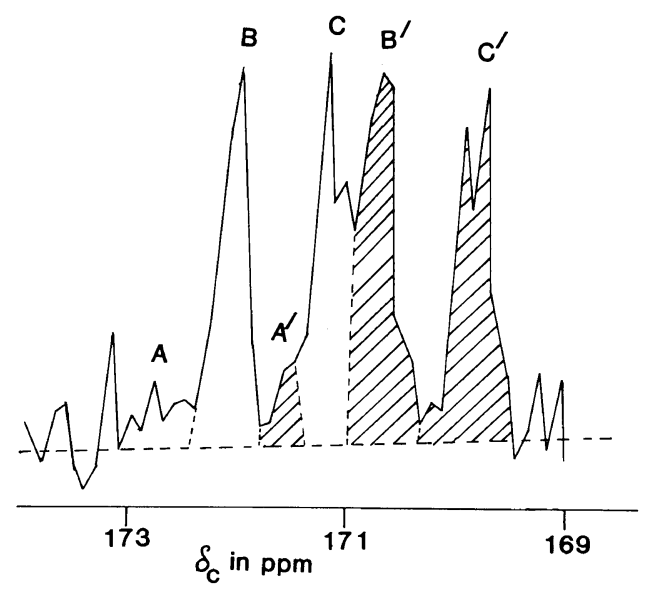

Figure 6. Expansion of the carbonyl carbon resonance pattern measured at $20 \mathrm{MHz}$ of the alternating copolymer of methyl $\alpha$-fluoroacrylate with styrene.

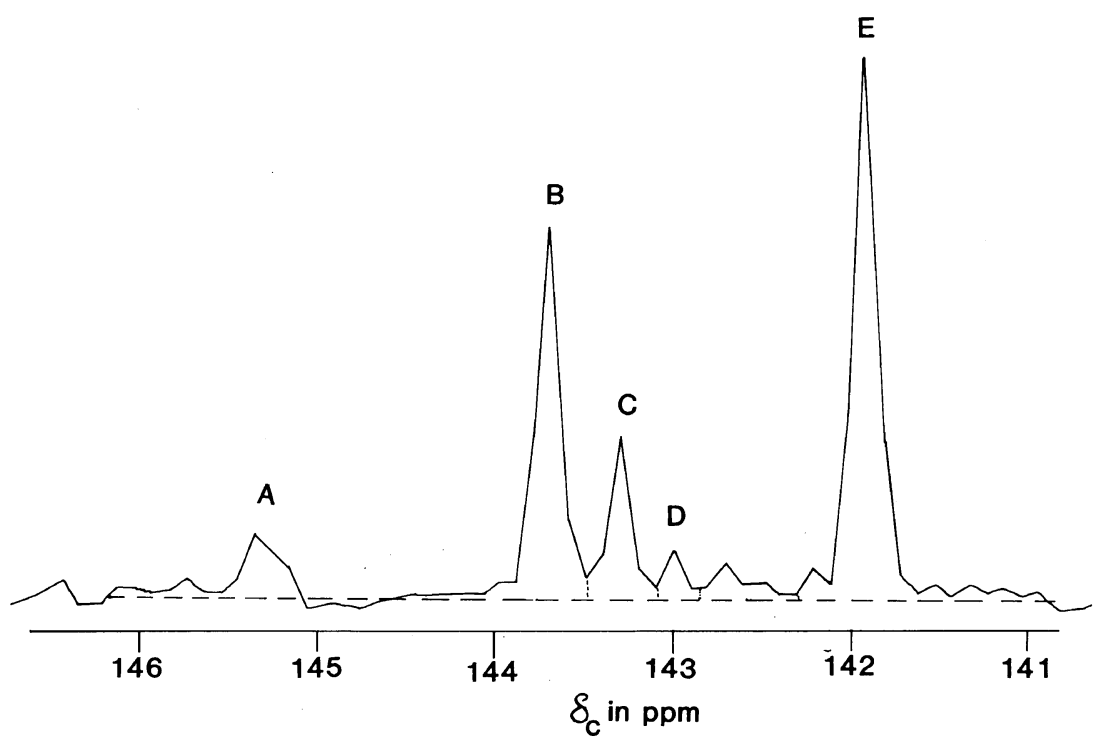

Figure 7. Expansion of the aromatic C-1 resonance region measured at $20 \mathrm{MHz}$ of the alternating copolymer of methyl $\alpha$-fluoroacrylate with styrene. 
stereosequences and if $\mathrm{C}$ and $\mathrm{C}^{\prime}$ are assigned to $\mathrm{mm}$-stereosequences, one can calculate that the relative intensities of signals $\mathrm{A}, \mathrm{B}$, $\left(\mathrm{A}^{\prime}+\mathrm{C}+\mathrm{B}^{\prime}\right)$, and $\mathrm{C}^{\prime}$ should be $0.06,0.22$, 0.50 , and 0.22 if $\sigma_{\mathrm{AB}}=0.66$. This corresponds well with the observed relative intensities.

Figure 7 shows an expansion of the aromatic $\mathrm{C}-1$ resonance region. It consists of five signals which are designated $\mathrm{A}-\mathrm{E}$ in order of increasing field. Table III provides the assignments for these resonances, along with measured relative intensities and relative intensities calculated for these signals assuming $\sigma_{\mathrm{AB}}=$ 0.66 . The relatively good agreement obtained between calculated and observed relative intensities indicates that most of the quaternary carbon resonance pattern can be attributed to MFA-S-MFA triads. Again, other minor resonances are observed in this region because of structural defects or impurities.

Figure 8 shows an expansion of the $\mathrm{CF}$ carbon resonances of poly(MFA-alt-styrene). Two oidentical patterns, separated by $194 \mathrm{~Hz}$ are observed. This separation corresponds to the carbon-fluorine spin-spin coupling constant for the $C F$ system. The signals in these patterns $\left(\mathrm{A}, \mathrm{B}\right.$, and $\mathrm{C}$ or $\mathrm{A}^{\prime}, \mathrm{B}^{\prime}$, and $\mathrm{C}^{\prime}$, in order of increasing field) are assigned in Table IV. This table also compares the relative intensities of these signals with relative intensities expected for them based on the assignments and a $\sigma_{\mathrm{AB}}$ value of 0.66 .

Figure 9 shows an expansion of the methoxy, methylene, and methine carbon resonance recorded at $20 \mathrm{MHz}$. This region of the spectrum was also studied at $75 \mathrm{MHz}$ and the spectra obtained are shown in Figures 9 and 10.

The methoxy carbon resonance $\left(\delta_{\mathrm{c}}=52.5\right.$ $51.3 \mathrm{ppm}$ ), as seen Figure 9, consists of three well defined signals, having relative intensities of $0.11,0.44$, and 0.45 , in order of increasing field. These were therefore assigned to $r r\left(\delta_{\mathrm{c}}=\right.$ $52.5 \mathrm{ppm}),(\mathrm{mr}+\mathrm{rm})\left(\delta_{\mathrm{c}}=51.9 \mathrm{ppm}\right)$, and $\mathrm{mm}$ $\left(\delta_{\mathrm{c}}=51.3 \mathrm{ppm}\right)$ stereosequences, the relative concentrations of which are calculated to be
Table III. Quaternary aromatic carbon resonance assignments for poly[(methyl $\alpha$-fluoroacrylate)-alt-styrene]

\begin{tabular}{|c|c|c|c|c|}
\hline \multirow{2}{*}{ Signal } & \multirow{2}{*}{$\frac{\delta_{\mathrm{c}}}{\mathrm{ppm}}$} & \multirow{2}{*}{ Assignment } & \multicolumn{2}{|c|}{ Relative area } \\
\hline & & & \multicolumn{2}{|c|}{ for $\sigma_{\mathrm{AB}}=0.6$} \\
\hline A & 145.30 & $r r$ & 0.09 & 0.12 \\
\hline B & 143.65 & $m r m m+r r m m^{\mathrm{a}}$ & 0.28 & 0.29 \\
\hline $\mathrm{C}$ & 143.24 & $\mathrm{rmrm}^{\mathrm{a}}$ & 0.11 & 0.10 \\
\hline $\mathrm{D}$ & 142.95 & $r m r r$ & 0.03 & 0.05 \\
\hline $\mathrm{E}$ & 141.90 & $m m$ & 0.45 & 0.44 \\
\hline
\end{tabular}

a $r r m m$ and $\mathrm{rmrm}$ may be reversed.

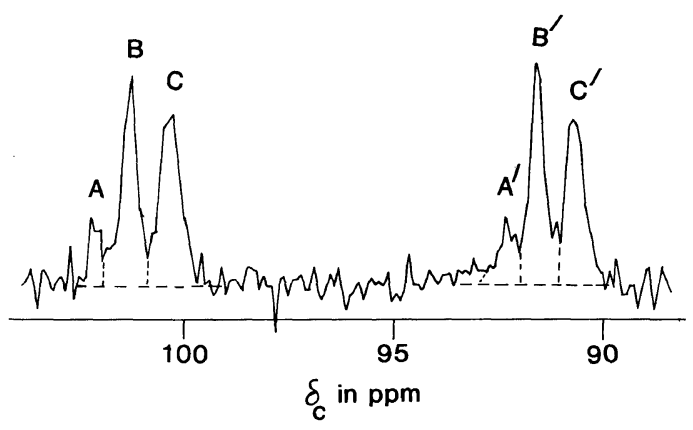

Figure 8. Expansion of the $\mathrm{C}-\mathrm{F}$ carbon resonance measured at $20 \mathrm{MHz}$ of the alternating copolymer of methyl $\alpha$-fluoroacrylate with styrene.

Table IV. CF-Carbon assignments for poly(MFA-alt-styrene)

\begin{tabular}{|c|c|c|c|c|}
\hline \multirow{3}{*}{ Signal } & \multirow{3}{*}{$\frac{\delta_{\mathrm{c}}}{\mathrm{ppm}}$} & \multirow{3}{*}{ Assignment } & \multicolumn{2}{|c|}{ Relative intensity } \\
\hline & & & Obsd & Calcd \\
\hline & & & \multicolumn{2}{|c|}{ for $\sigma_{\mathrm{AB}}=0.66$} \\
\hline A & 102.18 & $r r$ & 0.09 & 0.12 \\
\hline B & 101.27 & $m r+r m$ & 0.45 & 0.45 \\
\hline $\mathrm{C}$ & 100.30 & $m m$ & 0.46 & 0.44 \\
\hline $\mathrm{A}^{\prime}$ & 92.32 & $m m$ & 0.13 & 0.12 \\
\hline $\mathbf{B}^{\prime}$ & 91.71 & $m r+r m$ & 0.43 & 0.45 \\
\hline $\mathrm{C}^{\prime}$ & 90.79 & $m m$ & 0.44 & 0.44 \\
\hline
\end{tabular}

\section{$0.115,0.449$, and 0.436 if $\sigma_{\mathrm{AB}}$ is 0.66 .}

The methylene carbon resonance patterns $\left(\delta_{\mathrm{c}}=42-48 \mathrm{ppm}\right)$ differ considerably when observed at 20 and $75 \mathrm{MHz}$. This is due to carbon-fluorine spin-spin coupling. The effects 


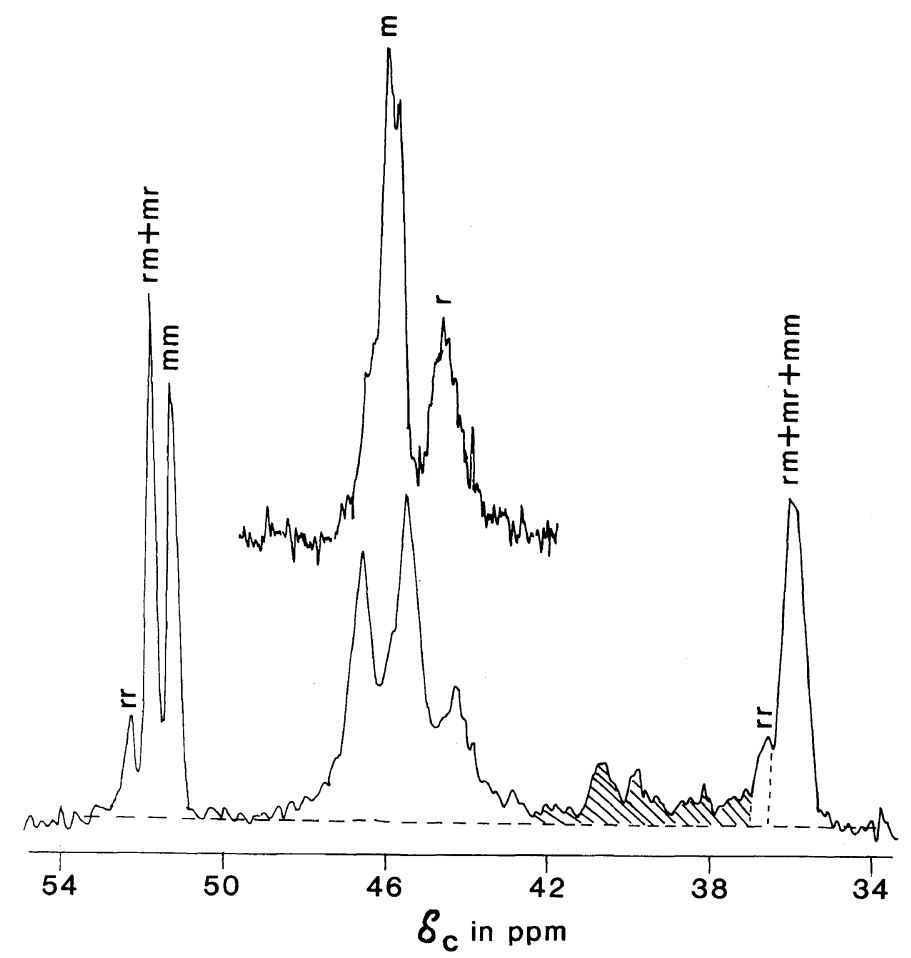

Figure 9. Expansion of the methoxy, methylene and methine carbon resonances recorded at $20 \mathrm{MHz}$ and $75 \mathrm{MHz}$ (inset) for the alternating copolymer of methyl $\alpha$-fluoroacrylate with styrene.

of such coupling are hardly noticeable in the $75 \mathrm{MHz}$ spectrum (Insert) and a two-signal pattern is observed. These signals were assigned to methylene carbons associated with $\mathrm{m}$ and $r$-dyads, in order of increasing field. Their relative intensities are 0.67 and 0.33 , again in good agreement with values of 0.66 and 0.34 that are expected if $\sigma_{\mathrm{AB}}=0.66$. The methylene carbon resonance as observed at $20 \mathrm{MHz}$ is believed to consist of two overlapped patterns having the same shape as that observed at 75 $\mathrm{MHz}$. The two patterns are separated by 22 $\mathrm{Hz}$, which corresponds to the carbon-fluorine spin-spin coupling constant for this situation.

Finally, the $75 \mathrm{MHz}$ methine carbon resonance pattern $\left(\delta_{c}=34-36 \mathrm{ppm}\right)$ consists of three signals that may be assigned to $r$, $(m r+r m)$, and $m m$ stereosequences in order of increasing field. The relative intensities of these signals are $0.11,0.42$, and 0.47 in Figure 10 . The $r r$ signal has a relative intensity of 0.12 in the $\mathrm{CH}$ pattern recorded at $20 \mathrm{MHz}$, but the $(r m+m r)$ and $m m$ resonances are not resolved.

The ${ }^{13} \mathrm{C}$ NMR spectrum of poly(MFA-altstyrene) thus contains many resonance patterns that contain information about its stereochemical structure. In all cases, the patterns indicate a $\sigma_{\mathrm{AB}}$ value of 0.66 .

\section{${ }^{19}$ F NMR Studies}

Figure 11 shows the $282 \mathrm{MHz}{ }^{19} \mathrm{~F}$ NMR spectrum of poly(MFA-alt-styrene) in $\mathrm{CDCl}_{3}$ solution at room temperature. In contrast to the ${ }^{19} \mathrm{~F}$ NMR spectrum of poly MFA, which is well defined and easily interpreted in terms of pentad stereosequences, ${ }^{17}$ the copolymer spectrum is poorly defined and difficult to interpret. In another paper, ${ }^{18}$ we show that this pattern is somewhat better defined in the spectrum of an alternating MFA-( $p$-fluorostyrene) copolymer than is the case here. In that case, pentad stereosequence assignments 


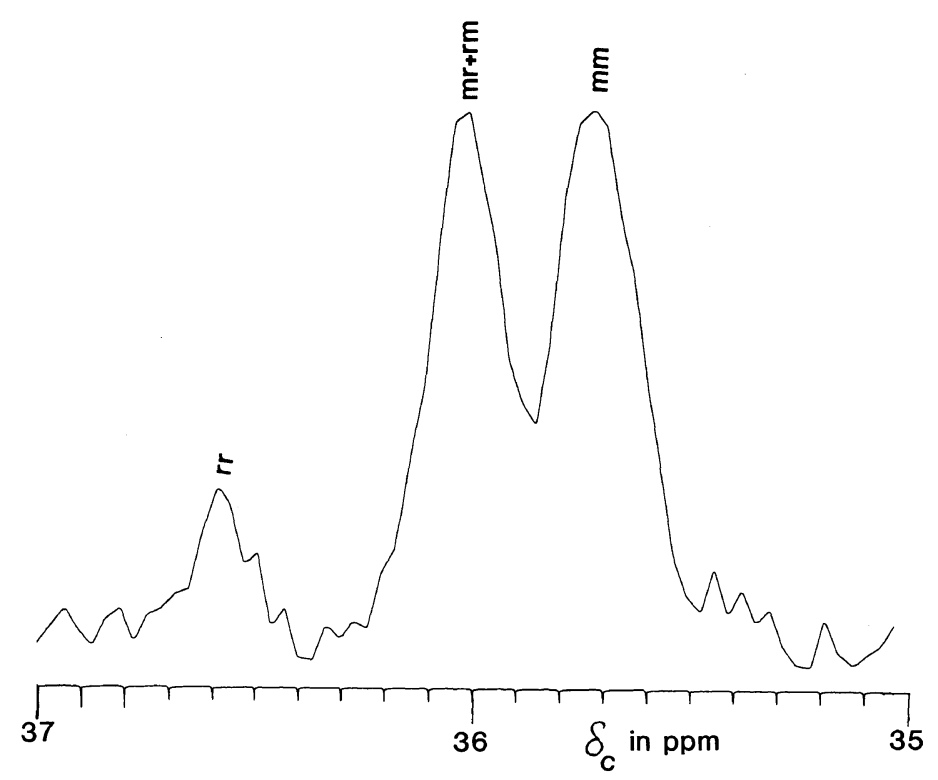

Figure 10. Expansion of the methine carbon resonance measured at $75 \mathrm{MHz}$ of the alternating copolymer of methyl $\alpha$-fluoroacrylate with styrene.

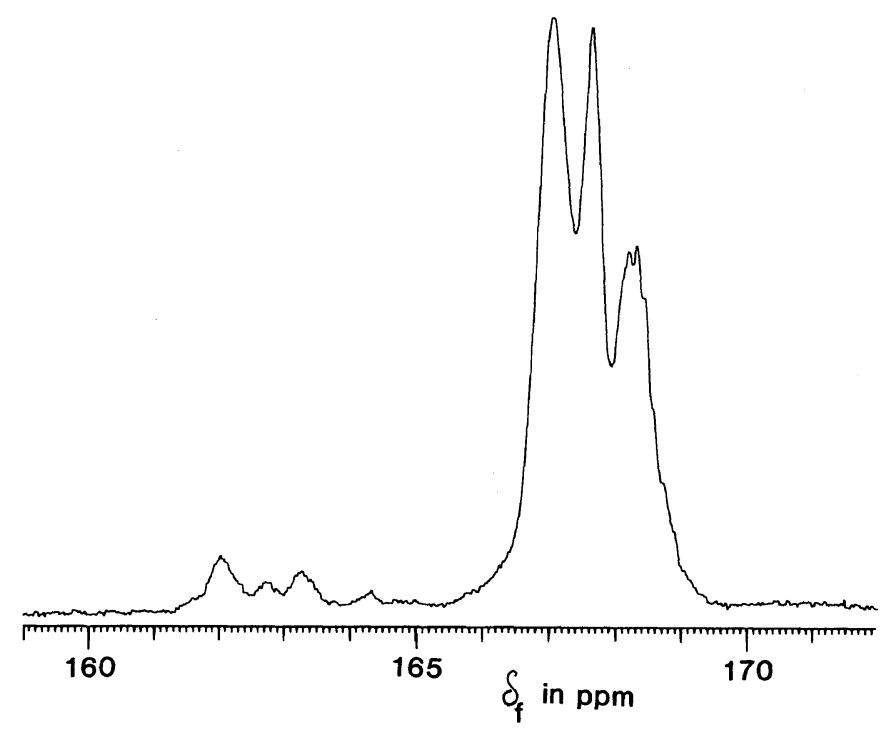

Figure 11. $282 \mathrm{MHz}{ }^{19} \mathrm{~F}$ NMR spectrum of the alternating copolymer of methyl $\alpha$-fluoroacrylate with styrene in $\mathrm{CDCl}_{3}$ solution at room temperature.

were proposed. On the basis of those assign- of resonances observed at $\delta_{\mathrm{F}}=161-165 \mathrm{ppm}$ ments, the resonances observed at $\delta_{\mathrm{F}}=168.5$ is attributed to $r$-centered pentads. The reland $167.8 \mathrm{ppm}$ are believed to be dominated ative intensities of the latter, which occur in by contributions from $\mathrm{mmmm}$ and $(\mathrm{mmmr}+$ four areas are $0.038,(0.015+0.021=0.036)$, rmmm) pentads, respectively, and the group and 0.011 , in order of increasing field. These 
are to be compared with values of $0.059,0.052$, and 0.013 that are expected for $m r r m$, $(m r r r+r r m)$, and $r r r$ pentads, respectively, assuming a Bernoullian stereosequence distribution and $\sigma_{\mathrm{AB}}=0.66$. Qualitatively, the spectrum can be considered to resemble the expected $0.115 / 0.449 / 0.436$ triad resonance pattern if the two highest field areas are taken as a measure of $\mathrm{mm}$ triads. Better evidence for this interpretation is provided by studies on the ${ }^{19} \mathrm{~F}$ NMR spectra of copolymers of MFA with $o$ - or $p$-fluorostyrene. ${ }^{18,19}$

\section{CONCLUSIONS}

The ${ }^{1} \mathrm{H},{ }^{13} \mathrm{C}$, and ${ }^{19} \mathrm{~F}$ NMR spectra of poly(MFA-alt-styrene) provide redundant evidence for its stereochemical structure. In all cases the resonance patterns observed are consistent with a coisotacticity parameter, $\sigma_{\mathrm{AB}}$, of 0.66 . Since a tendency for syndiotactic or cosyndiotactic enchainment is common in polymerizations of vinyl monomers that bear $\alpha$ substituents, a $\sigma_{\mathrm{AB}}$ value of 0.34 might seem more reasonable than the 0.66 value proposed in this work for the MFA-styrene system. The 0.66 value is based entirely on the methoxy proton resonance pattern observed for the copolymer and the resonances observed therein have been assigned by considering the effect of temperature on their chemical shifts. Should these assignments be incorrect, then the 0.34 value would apply and all assignments made in this paper must be reversed ( $m$ for $r$ and $r$ for $m$ ).

\section{REFERENCES}

1. K. Yokota and T. Hirabayashi, J. Polym. Sci., Polym. Chem. Ed., 14, 57 (1976).

2. K.-F. Elgert and B. Stützel, Polymer, 16, 761 (1975).

3. I. Kuntz and N. F. Chamberlain, J. Polym. Sci., Polym. Chem. Ed., 12, 1695 (1974).

4. B. K. Patnaik and N. G. Gaylord, J. Macromol. Sci., Chem., 7, 1247 (1973).

5. T. Hirabayashi and K. Yokota, J. Polym. Sci., Polym. Chem. Ed., 14, 45 (1976).

6. C. S. Marvel, J. Dec, H. G. Cooke, Jr., and J. C. Cowan, J. Am. Chem. Soc., 62, 3495 (1940).

7. A. L. Henne and C. J. Fox, J. Am. Chem. Soc., 76, 479 (1954).

8. R. N. Majumdar and H. J. Harwood, Chem. Ind. (London), 650 (1981).

9. R. N. Majumdar and H. J. Harwood, Synth. Commun., 11, 901 (1981).

10. E. Elkik, R. Dahan, and A. Parlier, Comptes rendus, série $C, t$. 282, 1129 (1976).

11. C. U. Pittman, Jr., M. Ueda, K. Iri, and Y. Imai, Macromolecules, 13, 1031 (1980).

12. A. A. Bothner-By and S. M. Castellano, "Computer Programs for Chemistry," Vol. 1, D. F. DeTar Ed., W. A. Benjamin, Inc., New York, N. Y., 1968.

13. L. A. Wall, D. W. Brown, and V. E. Hart, J. Polym. Sci., 15, 157 (1955).

14. L. A. Wall and D. W. Brown, J. Phys. Chem., 61, 129 (1957).

15. G. Filipovich and G. V. D. Tiers, J. Phys. Chem., 63, 761 (1959).

16. F. A. Blouin, Ph. D. Thesis, University of Akron, 1975, Diss. Abstr. Int. B, 36, 2256 (1975); available from University Microfilms, Ann Arbor, Michigan, order No. 75-23,969.

17. R. N. Majumdar and H. J. Harwood, Polym. Bull., 4, 391 (1981).

18. R. N. Majumdar, H. J. Harwood, and F. T. Lin, Polym. Prepr. Am. Chem. Soc., Div. Polym. Chem., 24(2), 134 (1983).

19. R. W. Majumdar, H. J. Harwood, and F. T. Lin, to be submitted for publication. 